\title{
The future of social anthropology
}

What is the future of the disciplinary label 'social anthropology'? This question, of central concern to the European Association of Social Anthropologists, was the main topic that occupied a group of around fifty scholars who met in May 2004 at the Institute of Social Sciences of the University of Lisbon. ${ }^{1}$

In 1989, Adam Kuper chaired a similar meeting in Castelgandolfo, near Rome, where very much the same issue was debated ${ }^{2}$ and where it was concluded that, in a newly unified Europe, social anthropology had an important role to play. As a result, the European Association of Social Anthropologists was formed and has grown considerably ever since. Fifteen years later, when a whole new region of Europe enters into the European Union, bringing with it its own specific intellectual traditions and perspectives, it seems particularly appropriate to re-launch the debate. ${ }^{3}$ In this article I discuss some of the issues that preoccupy me most concerning the contemporary role of sociocultural anthropology ${ }^{4}$ in Europe and around the globe.

\section{A metatradition}

Two years ago, the newly founded Max Planck Institute for Social Anthropology in Halle am Saale, Germany, celebrated its opening with a set of conferences entitled 'The Four Traditions', at which distinguished colleagues were asked to present what were seen as the four major trends of anthropological thought: the German, British, French

1 In my double role as local convener of the meeting and President of EASA, I thank the Institute of Social Sciences, the Foundation for Science and Technology of the Ministry of Science and Higher Education of Portugal, and also the Calouste Gulbenkian Foundation and the embassies of Spain and France for their financial support. [Editorial note. Time-constraints prevented this essay being published, as originally intended, in the previous issue of Social Anthropology, alongside the three other key addresses given at the Lisbon meeting, by Adam Kuper, Philippe Descola and Marilyn Strathern.]

2 That meeting was made possible through the financial support of the Werner-Gren Foundation for Anthropological Research and the special encouragement of its then president, Sydel Silverman.

3 The present text has benefited considerably from the comments made to me by a number of colleagues who participated in this event. I specially want to acknowledge the richness of the debate I have had with André Gingrich, first in Halle am Saale, then in Lisbon and still later in Vienna, at the time of EASA's eighth biennial conference. His still unpublished paper 'Changing contents in shifting contexts. An essay on the status of socio-cultural anthropology in the German-speaking countries' provided me with further inspiration. I am also grateful for Peter Pels for his wise editorial comments.

4 I think it can safely be stated that, for many anthropologists today, the difference between social and cultural anthropology is more an issue of institutional than of theoretical relevance. 
and American traditions. I was privileged to have been invited to attend this meeting. But, as the days went by and we engaged our colleagues in debate over their brilliant presentations, ${ }^{5}$ I became aware of an increasing sensation of discomfort. I could not help asking myself: 'Precisely to which of these traditions do you belong?'

Now, as it happens, my own particular history made it difficult for me to identify predominantly with any of the larger imperial traditions. I freely acknowledge that to write the history of anthropology we may need to postulate the existence of such traditions, but I feel that the present relevance of these lines of intellectual heritage is highly doubtful. We should not be bound by them. In order to clarify what I mean, let me recount two sets of events that happened to me a few years ago.

When I visited Fei Xiao Tung's department at Beida University in Peking, I was met by a group of bright young anthropologists. ${ }^{6}$ These Chinese colleagues protested vigorously against the style of descriptive and politically controlled research they were being forced to undertake. They hoped one day to be able to carry out the sort of methodological exercise that I myself was undertaking at the time, in Macao in southern China (cf. Pina-Cabral and Lourenço 1993; Pina-Cabral 2002). I tried to engage them in debate over the work of the British, French and American sinological anthropologists that I was then reading with great profit. They did not show much interest, arguing that there was little benefit for them in reading the work of people who would never be able fully to understand China. Somehow, however, they found out that I had been privileged personally to meet Sir Edmund Leach. We spent the rest of the afternoon in a heated debate about his work and ideas.

Later in the same year I visited Rio de Janeiro for the first time and was taken to dinner by a colleague of ours, Lygia Sigaud, who impressed me tremendously by the breath of her knowledge of Leach's work and personality. Does this mean that Fei's students in Peking, Lygia's students in Rio and my own students in Lisbon are all part of the 'British tradition'? I do not believe so. True, we all share a similar fascination with the work of Leach. But we read equally avidly Weber, Simmel, Mauss, Lévi-Strauss, Benedict, Dumont, Turner, Geertz and a motley assortment of other brilliant anthropologists who have come to constitute a kind of loosely defined global canon.

I therefore conclude that most present-day anthropologists cannot be said to belong to one of the 'four traditions'. The time for that has long passed. Rather, we are all members of a kind of metatradition: that is, the intellectual common ground that has emerged from the global interbreeding of the many strands of modernistic anthropological thinking that, for a few decades during the mid-twentieth century, seemed to be developing separately. I have chosen to call this a 'tradition' as - much like the modernist traditions - it reproduces itself by means of the negotiation of a (loosely defined and constantly shifting) canon. It does, however, exhibit important differences as it is permeated by a plurality of sub-traditions - French, Portuguese, Dutch, Japanese, and so on - that correspond to linguistic sub-spheres that exist largely independently.

Today's world is a space where communication is increasingly easy to achieve. Anthropologists may diverge in their ways and visions, but in one thing they are all very similar: they are good travellers and good communicators and they often

6 In China, they call themselves more often 'sociologists', much as many Indian anthropologists do, since the term 'anthropology' is still associated with the study of 'exotic' peoples. 
cross the world. They have a taste for opening windows, so to speak. We are all subject to the intellectual influence of the works of colleagues from other places; our conferences are increasingly visited by colleagues from other lands; our publications are read worldwide; our electronic debates reach across the oceans. The relatively local intellectual universes within which we carry out our teaching and early training (which in any case often occur in languages other than English) are constantly penetrated, altered and challenged by universal trends that can no longer be kept at distance and that compel us to respond all of the time. At the same time, thanks to their relative independence, these local intellectual universes play an important role in a more globalised interaction (now conducted largely in English); they function as spaces in which intellectual reproduction can carry on in relative independence of the global hegemonic voices.

Whether we like it or not, today's anthropology has become increasingly symmetrical. ${ }^{7}$ Faced with a major change in the nature of international relations at the time of decolonisation, the anthropologists of the 1950s and 1960s endeavoured to take anthropology towards new fields, leaving behind an association with colonial spaces and 'primitive' societies that had so deeply marked the high modernist period of our discipline. In this way, they made it possible for anthropology to be practised everywhere, even by those who were not in the imperial camp. They universalised the practice of anthropology and de-centred its object.

Furthermore, half a century later, university education has become available in places and to people who previously had no access to it. Anthropologists are being produced in small and large universities all over the world. Wherever we go, whether it be Andalusia, Yucatán, Bahia, Calcutta, Maputo, Novosibirsk or Bucharest, we meet up with local colleagues who often know our work, and who have been trained by reading the same modernist classics that formed us. Local differences, fortunately, do exist. But our sense of proximity with these colleagues can only increase in coming years.

\section{Is anthropology a 'western' endeavour?}

In the light of what was said above, and considering the central role that is usually attributed to 'otherness' in anthropological narratives of self, it is somewhat surprising that the concept of 'alterity' has not been more analytically elaborated in our debates. ${ }^{8}$ In fact, of late, the pervading culturalist winds have tended to reduce discussions of alterity to the opposition between 'the west and the other'.

While supposedly associated with a counter-hegemonic anti-imperialist posture, this overemphasis on the westernness of science seldom has greater intellectual impact than the reflexive drawing-out of 'otherness' and the hiding of the universal nature of the intellectual heritage that went into building up modern science and scholarship. The constant self-accusation about anthropology's past and its essential 'westernness' we indulge in ends up hiding the complexity of the interactions that went into the construction of the anthropological discourse we have received. Instead of drawing out

7 I am, of course, inspired in the use of this concept by Bruno Latour's essay on modernity (1994 [1991]), although I do not feel bound to accept all of the implications he attributes to the term.

8 I, for one, find that treatments of the notion, such as Michael Taussig's Mimesis and alterity (1993), enter into the complexities of the issue before addressing the basic perplexities. 
this complexity and allowing for more symmetrical forms of negotiation of our common global canon, this type of critique ends up by contributing towards the validation of the separateness of 'the west'.

This point may be seen to emerge from the work of a number of recent authors. For example, Cecilia McCallum, in her ethnography of the Cashinaua, a people who live in the Peru/Brazil border region, states:

If the Indians are special and different, their difference is deeply entwined not just with many millennia of barely glimpsed historical change and development, but also with five hundred years of immersion in a history that began as European and mutated into a global one. And if I may be deemed a unique 'self', I must admit to the most diverse influences and embodied experiences that make me, if not a 'partial' being, at least a complex one (2001:1-2).

In writing these notes, I was inspired by the philosophical writings of Emmanuel Lévinas (eg. 1996). Lévinas warns us against the dangers of polarising alterity. He calls our attention to the fact that the culturally elaborated categories of social belonging on which anthropologists have traditionally focused co-exist with another, far more constitutive, form of alterity: an interpersonal, face-to-face human interaction that implies a deep and unavoidable sense of ethic co-responsibility. He warns us that 'alterity [cannot] be justified uniquely as the logical distinction of parts belonging to a divided whole, which rigorous reciprocal relations unite into a whole' (1996:165).

While modernist anthropologists have focused on the latter type of alterity, they have tended to forget about the former: the face-to-face confrontation, the basic fraternity that is constitutive of our own selves as humans (cf. Fabian 2002). This disposition that we carry within ourselves to recognise the humanity in others ${ }^{9}$ is what makes radical ethnography possible. Otherwise, how could a person enter a cultural world of which he or she had no previous knowledge and learn to function within it? Modernist social theory has placed such a strong emphasis on group belonging (on 'society' and 'culture' as integrated wholes) that it has shunned this other form of alterity. By doing so, however, it has made itself blind to the moral and cognitive implications of the permanent co-existence in human behaviour that these two registers of alterity represent. Thus, I adopt Lévinas's critique of the logic of totalisation implicit in the history of European thought, where we necessarily approach others as belonging to 'such and such a type' (Lévinas 1996:166). In his words,

One must precisely place in question the conception according to which, in human multiplicity, the ego would be reduced to part of a Whole, which reconstitutes itself in the image of an organism or a concept - whose unity is the coherence of its members, or a comprehensive structure (Lévinas 1996: 165).

In my understanding, my posture here is akin to that of the authors who have recently been working with the concept of 'sociality'.

Basic fraternity is a condition of all human sociality, but is constantly subject to the strains of political belonging: that is, to the culturally elaborated forms of alterity that our discipline has studied so extensively. Again, according to Lévinas, anthropology's role in European modernity was precisely that it responded to a sense of contradiction in the consciousness of Europeans. He argues that Europe's humanist ideals of peace

9 What another philosophical school (Donald Davidson) would call 'interpretive charity'. Cf. PinaCabral 2004. 
and truth, inherited from a long philosophical tradition going back to ancient Greece, were flagrantly challenged by the fratricidal nature of Europe's history. Faced both with its internal failure and with a sense of remorse for those it oppressed, Europe looked beyond itself 'in order to seek the entire universe in self-consciousness' (Lévinas 1996: 163).

No one will deny that this self-questioning thrust is a central driving force in the history of our discipline. However, when the post-war generation of anthropologists started bringing their search for alterity nearer and nearer to their ideological home ground, this universalism turned upon itself. There was a de-centring of alterity not only in that 'we' were now looking at 'ourselves' as other, but also because the very instrument of looking was universalised. Fei Xiaotung, Kenyatta, Srinivas, C. K. Yang, Franz Steiner ${ }^{10}$... long is the list of anthropologists who made a lasting mark on our discipline and whose claim to 'otherness' before some sort of European/western centrality is undeniable.

Thus, I suggest that European anthropologists have lessons to learn from our colleagues of other continents. Some of these intellectual traditions - as in India or Brazil $^{11}$ - have been going on for over half a century and have generated important insights into ways of dealing with their own compatriots as same and other that we could usefully learn from in Europe.

Over twenty years ago, T. N. Madan argued that anthropology,

is not a western discipline which is to be enriched . . by feedback from other parts of the world. Nor is it the rhetoric of counterattack from the Third World. It is an empirical discipline, the data base of which has to be broadened to take in the whole world, without locating its centre today in the place of its historical origin (Madan 1982: 268).

In spite of the difference in our mutual subject positions, I identify with his almost prescient attempt to free anthropology from the binds of identity politics. ${ }^{12}$

We have to be wary of all types of attribution of historical and civilisational unanimity to 'the west'. This all-too-common practice plays a curious ideological role when applied to the history of science, as it automatically throws a veil of silence over the historical and cultural complexity of the intellectual and technological heritage that went into making what today passes as 'western' erudite culture and science. As a matter of fact, it is all too easy to pass from the observation that there is some sort of historical coherence to western civilisation to a programmatic 'westernist' type of attitude.

Colleagues who insist that we have not one anthropology but rather various 'anthropologies', that there is not one science but various sciences, are emphasising a very dangerous kind of truism. While on the one hand no two persons ever think absolutely alike - and, consequently, no two communities of scientists can

10 Note the influential role that Franz Steiner played in post-war anthropology in Oxford and his radical denial of his own 'westerness' as a Jew from Eastern Europe (Steiner 1999, I:40, 47-8). I am grateful to Richard Fardon for drawing my attention to this point.

11 For example, Trajano Filho and Lins Ribeiro 2004.

12 While it is clearly not possible to develop this argument here, it is worth noting that an epistemological confusion often lies at the root of these anthropological debates. Contrary to the sceptical approach that has come to dominate our ranks, I feel closer to the type of 'minimalist realism' advocated by thinkers such as Michael Lynch (1998). 
share absolutely the same understandings - on the other hand, it is clear that those who insist on the plurality of anthropology run the risk of silently engaging in the construction of borders. They mean to be politically correct, allowing 'the other' her or his right to difference. In fact, however, their 'progressive' cultural relativism ends up contributing towards a reinforcement of borders. Instead of taking on board the de-centring involved in the dialogue with 'the other', their benevolence closes the borders to a constructive joint discourse. While apparently acknowledging the right of others to difference, they run the risk, unwillingly, of further naturalising 'the west'.

As argued earlier, I plainly acknowledge that there are different sub-traditions of intellectual discourse that reproduce themselves with a measure of independence within the global anthropological discourse. Their relative independence may in fact be a potent means of questioning global hegemonies. But we must also agree that these are no longer 'traditions' in the sense that characterised the 'four traditions'. Today's largely linguistic subtraditions work within a globalised world of interchange which functions like a constantly present metatradition: it is constantly active even within more local debates. In order better to challenge present-day ideological hegemonies and their manifestations within global anthropology, we must not argue for the equal validity of different 'anthropologies' (a kind of separate development) but rather for the essential identity and mutual relevance of all anthropological discourse. ${ }^{13}$

There is no better evidence of the potentially dangerous implications of such a posture than the generalised practice in Anglo-American anthropological circles of not quoting works by colleagues closer to the ethnographic region that are written in languages other than English on the basis that they are not of direct relevance to English-language readers. Often, however, the languages in question (Chinese, Japanese, Arabic, German or Portuguese) correspond to longstanding and fully developed learned traditions to which a large part of the anthropological reading public has access. As quoting and citing are the basic stuff of academic recognition in our globalised academic world, this apparently innocent gesture amounts to a sinister tool for silencing other academics.

On the contrary, whoever aims to promote a more symmetrical anthropology must surely identify the marks of 'westerness' in their own thought as obstacles to overcome. Contrary to what we are told by those who choose to simplify the history of our discipline, such concern to avoid what used to be called 'Eurocentrism' has been an integral part of our discourse for a very long time, even if it has not always been equally well achieved. However, contrary to the recent brand of culturalism, the relativism implicit in such a posture was methodological rather than cultural and programmatic; it aimed ultimately to promote knowledge about human culture and society that would be as universal as possible. ${ }^{14}$

At this point, it is worth noting (a) that the local sub-traditions are bearers of hegemonies just as much as the metatradition; and (b) that there cannot be any shared mode of debate that does not bear hegemonies.

14 Note that there is no contradiction in my mind between such a posture and that of those who see anthropological theorising as closely linked to ethnography, as in McCallum's dictum that 'there is no anthropology that is "more than" ethnography, no free-flying methodology, no theory to be articulated without the colour, taste and smell of empirical description' (McCallum 2001:1). 
How has it come about that most contemporary anthropologists suddenly fall silent when faced with questions about 'universalism' or 'humanity'? This is surely a sign that we badly need to rethink how we approach our anthropological purpose.

\section{A symmetrical anthropology}

Time has come to acknowledge openly that, as Madan insists, the critical process of breaking with the frontiers of westerness has been an integral part of the tradition of anthropology for a very long time. I fully share his 'muted unease about the exclusivism of the idea of anthropology as the study of "other cultures"' and I take up his 'plea for anthropology as the mutual interpretation of cultures and, ultimately, of critical self-awareness' (Madan 1994: ix). As the job of anthropological analysis progressed during the latter part of the twentieth century, a more symmetrical approach to our task emerged (one that fully deconstructed the 'primitivism' that earlier anthropology had constructed [cf. Kuper 1988]). As more and more people took to the practice of anthropology throughout the world, we witnessed a re-drawing of the relation between the anthropologist and her object (the native, so to speak). In EASA, at least, we are increasingly conscious of the way in which the condition of being an object of study has been radically relativised. Any one of us can be, at the same time, the subject and the object of anthropological analysis. When Portuguese anthropologists meet with Brazilian colleagues, for example, we are as likely to be discussing Portugal as Brazil; as likely to be studying Amerindians as Portuguese city dwellers, Ukranian migrants to Portugal or Japanese Brazilians in Japan.

In their plurality, in both a theoretical and a physical sense, anthropologists today come from different places. They may be working towards divergent destinies but their paths constantly cross; that means that the plurality of anthropology cannot be understood as a denial of the value of anthropology as a meeting point, but rather as the empirical confirmation of that value. We may have difficulties in finding precisely what defines us as anthropologists, but we seem to have no difficulty finding out what brings us together to debate. My own engagement as a teacher of anthropology in Europe, Macao, Mozambique or Brazil has brought this out to me very vividly.

Nor should the fact that we speak English to each other be taken to mean that our minds have somehow been won over by Anglo-American culture. Such a conclusion cannot be reached for India, for China, for Japan or for Brazil, where an increasing number of people are also learning to speak English. Why should it apply in Europe? On the contrary, I am convinced that we are capable of negotiating global cultural hegemonies to the point that we can sustain forms of reasonably independent cultural and scientific development.

The anthropological heritage allows us to be hopeful on that front. The making of modern anthropology was not the work of one single empire, of one sort of person or of one single nation or language. Hearing some of our colleagues of late, we might be tempted to despair and to think that all past anthropologists were British or French male colonialists and equally that all contemporary anthropologists are practitioners of a culturally specific western mind-exercise. But one can state emphatically that this was not the case. I, for one, see no sufficient historical evidence to give up the universal claims of science and, in particular, the universal hopes of anthropological knowledge. 
Among the social sciences, anthropology is in fact especially well positioned to carry out the task of policing the way in which these universal aims are put into practice.

\section{Anthropology in Europe}

Contrary to what some of our politicians appear to believe, there does not seem to be any evidence to suggest that in the foreseeable future most European scholars will be living in an American type of system for the production of scientific knowledge. Rather, most European scholars will continue to be civil servants, paid more or less reasonable middle-class salaries that remain largely independent of their level of personal achievement, and will continue to be associated with cherished local traditions of linguistic and intellectual specificity (regional, ethnic or national).

Europe is a place in which different linguistic and academic traditions are not about to merge in some sort of cultural melting-pot. Such homogenisation is not to be foreseen, nor is it to be desired. In Portugal, at least, speaking English does not make us feel any the less Portuguese. It is no surprise, therefore, to observe that in Europe different socio-scientific heritages have survived, and that we are far from all being in full agreement about the nature of our discipline.

EASA is not the only association that exists in our field. Other organisations, with different histories, have survived and are acquiring new life. In particular, a new historicist trend of ethnology and folklore associated with museology has surfaced over the past decade as a result of the impact of American culturalism on the older ethnological schools that survived in eastern and southern countries where, for political reasons, the impact of modernist anthropology was less strongly felt. Moreover, the old relations with physical anthropology and archaeology are also far from extinct and are similarly undergoing new and interesting developments. In particular, the debate between anthropology and the health sciences is revitalising areas of our discipline that had lain dormant for a considerable amount of time.

I believe that a broadly defined field of scientific debate has been established around the canon of sociocultural anthropology and its associated ethnographic methodology. Some wish to define it in one way, others in another; but, on the whole, such a field is largely recognisable. Malinowski, Mauss, Lévi-Strauss, Leach, Turner or Geertz, to name only a few, are read and cherished by all anthropologists. In regions of the globe such as ours, there are special benefits in working around a common terrain of scientific convergence such as that provided by our global anthropological heritage. What do we do in EASA, when we meet biannually, if not nourish that common ground? EASA's conferences have been a great success and are here to stay. They clearly meet a real need.

\section{Re-affirming the anthropological common ground}

As argued above, anthropologists have rather too readily agreed to define their discipline through its relation to a notion of 'otherness' that is surprisingly impoverished from a theoretical point of view. We know full well that all human 'others' can only be 'others' to the extent that they are the same in a very important way. But the search for that sameness involves us in a whole range of theoretical wrangles that most of us prefer to avoid; the result has been a single-minded emphasis on 'difference' as the factor defining our field. 
Faced with this situation it is no wonder that our disciplinary label has come to appear old-fashioned and undesirable. But have we stopped being fascinated by the common heritage that defines this loose anthropological common ground? Clearly not. The Chinese, Indian, Brazilian and European cases to which I have referred should be enough to prove that there may well be a problem with the label 'anthropology' but not with the practice of anthropology.

Thus, as we and our students continue to be fired intellectually by anthropology, and as we find within the discipline an indispensable common ground for scientific debate, we are faced with having to reproduce it: we need to finance projects, to organise teaching programmes and find posts for our best post-doctoral students. Faced with the paradox, we resolve it by escaping laterally and, as so often happens with academic economics, we attempt to hide disciplinary 'reproduction' under the guise of the 'production' of new academic products.

This can be done in essentially two ways: on the one hand, less effectively, through the multiplication of sub-disciplinary fields (urban anthropology, medical anthropology, political anthropology, visual anthropology, and so on); and on the other hand - more efficiently but much more disturbingly - through the production of fashion-driven alternative disciplines. Since the 1970s, we have witnessed the rise and fall of 'development studies', 'gender studies', 'race studies', 'ethnomethodology', 'media studies', 'cultural studies', 'postcolonial studies', and others.

Scholars trained as anthropologists invent these labels to circle round what is perceived as a non-sexy discipline. In this way they aim to open new doors in a reasonably closed labour market, to increase book sales, to increase their departmental income or to create new posts. Unfortunately, it is nothing but a mirage: after each 'this-and-that studies', another 'this-and-that studies' promptly arises. Fashions follow one another in a dramatized succession of apparent breakthroughs that all too soon vanish into irrelevance.

It is not against the dramatisation of academic succession that I rant. Rather, it is against the way in which this 'studies mode' has undermined anthropology. My concern is that as all these sub-disciplines and 'studies' come and go, our anthropological common ground is weakened. We have allowed the discipline to be eroded by our disputatious claims to have invented more efficient ways to place our knowledge. In the end, we find our depressing prophecies confirmed. Bookshops no longer carry anthropology sections; libraries have started to re-catalogue our books; publishers' editors have interiorised the outrageous and highly debatable theory that no one reads monographs; colleagues in neighbouring disciplines no longer realise that what is influencing their work is yet another outcrop of anthropological theory or another manifestation of the ethnographic tradition of research; NGOs and government agencies are blind to the impact that anthropological knowledge has had on their everyday work; funding agencies find that they have no good reason to subsidise independent anthropological research.

In much the same way that we have allowed 'primitiveness' to define our field among the general public (in spite of having ourselves rejected the concept decades ago) we have allowed a museological, old-world odour to permeate our common academic enterprise. What we do that is creative and new tends to be labelled not as anthropology but as 'this-and-that studies', particularly of late in English-language publications. At the root of this problem lies our difficulty in resolving the metaphysical scepticism that has beleaguered anthropological theory over recent decades. I do not propose to 
address such a major issue here. But I cannot accept that the common ground of our intellectual engagement should become something that we approach with vague feelings of regret. Anthropology has to re-encounter its universal claims, no longer on the basis that at the bottom of each us lies a primitive, but rather on the basis of a symmetrical approach to the play of sameness and difference.

\author{
João de Pina-Cabral \\ Institute of Social Sciences \\ University of Lisbon \\ Avenida Professor Aníbal de Bettencourt, 9 \\ 1600-189 Lisboa \\ Portugal \\ pina.cabral@ics.ul.pt
}

\title{
References
}

Barth, Frederik, André Gingrich, Robert Parkin and Sydel Silverman. 2005. One discipline, four ways. British, German, French and American anthropology. Chicago: Chicago University Press.

Fabian, Johannes. 2002. Time and the other. How anthropology makes its object. New York: Columbia University Press.

Kuper, Adam. 1988. The invention of primitive society. Transformations of an illusion. London: Routledge.

Latour, Bruno. 1994 [1991]. Jamais fomos modernos. Ensaio de antropologia simétrica [translated by Carlos Irineu da Costa]. São Paulo: Editora 34.

Lévinas, Emmanuel. 1996. Basic philosophical writings [edited by A. Peperzak, S. Critchley and R. Bernasconi]. Bloomington: Indiana University Press.

Lynch, Michael. 1998. Truth in context. An essay on pluralism and objectivity. Cambridge, MA: MIT Press.

Madan, T. N. 1982. 'Indigenous anthropology in non-western countries. An overview', in Hussein Fahim (ed.), Indigenous anthropology in non-western countries. Durham, NC: Carolina Academic Press.

1994. Pathways. Approaches to the study of society in India. Delhi: Oxford University Press.

McCallum, Cecilia. 2001. Gender and sociality in Amazonia. How real people are made. New York: Berg.

Pina-Cabral, João de. 2002. Between China and Europe. Person, culture and emotion in Macao. London: Continuum.

2004. 'Os albinos não morrem. Crença e etnicidade no Moçambique pós-colonial', in F. Gil, Pierre Livet, and João de Pina Cabral (eds.), O processo da crença. Lisbon: Gradiva.

Pina-Cabral, João de and Nelson Lourenço. 1993. Em terra de Tufões. Dinâmicas da etnicidade macaense. Macao: Instituto Cultural de Macau.

Steiner, Franz Baermann. 1999. Selected writings. Volume I: Taboo, truth and religion [edited by J. Adler and R. Fardon]. New York: Berghahn.

Taussig, Michael. 1993. Mimesis and alterity. A particular history of the senses. London: Routledge.

Trajano Filho, Wilson and Gustavo Lins Ribeiro. 2004. O campo da antropologia. Recife: ABA. 